Editorial

\title{
Women in COVID-19 Pandemic: Influential Leadership is the Need of the Hour
}

\author{
Poonam Malhotra Kapoor ${ }^{1}$ \\ ${ }^{1}$ Department of Cardiac Anaesthesia, Cardio Thoracic Centre, \\ All India Institute of Medical Sciences, New Delhi, India \\ Ind J Car Dis Wom:2020;5:271-273
}

\section{Introduction}

Since its initial spread, the COVID-19 pandemic is bringing forth new challenges for medical personnel as well as the general public.

Shakespeare referred to women as the "fairer sex.." This is ironic, considering the unfair situations women find themselves in in society today! Surprisingly, the Coronavirus is treating women more kindly than their male counterparts! Is it better immunity, by virtue of the "X chromosomes effect," or is it, the innate ability in the females of all mammal species to cope with stress much better than their male counterparts? Let us debate as to how women are indeed stronger than men in stressful times!

\section{Perpetuation and Sustentation is then Need of the Hour}

The dictionary meaning of the word female comes from the Latin "femella," the diminutive form of the word "women." It is not etymologically related to the word male. In the 14th century, the spelling was altered in English to parallel the spelling male.

A woman safeguards peace at home, in society, and at the workplace. This messiah of peace, too, needs to shield herself against the deadly COVID-19 pandemic. Is her own biologic inner milieu adequate to bear the unknown viral onslaught? This special edition of IJCWD deals with such issues and the editor and her team need to be complemented for bringing out the timely, "need for separate scientific guidelines for the fecund and stalwart population" against the pervasive, rampant, and universal onslaught of SARS-CoV-2 in 2019-2020.

\section{Do Women Fare Better in Pandemics?}

The hormone testosterone makes it easier for men to be physically stronger than women. This is an evolutionary survival mechanism and selection method that has been used through the ages, so that the "males" of the species can protect and safeguard the "females" for continuum of life, as females are essential for species propagation. However, God's mandate is not followed by too many men, who corrupt the Godly intended order of things by committing violence against women! This pandemic should not take couples back to the 1950's!

When it comes to living through pandemics, however, women are twice as strong as men! The difference lies in the case fatality rate, as quoted in the Guardian in Italy, Spain and even China, which was twice in men compared with women (China $2.8 \%$ in men vs. $1.7 \%$ in women). Even post lifestyle corrections like not smoking, wearing masks, and observing social distancing has not led to a dip in the case fatality rate!

\section{Pandemic Opens Pandora's Box of New Problems}

This pandemic has opened up multiple issues to be dealt with simultaneously in hospitals as well as in communities. The physiological events and pathological comorbidities are posing problems for women during this pandemic, especially in view of health services being overburdened. Around the world, women form $70 \%$ of workers in the health and social sector. Therefore, in the COVID-19 pandemic, like other pandemics, they constitute the majority of frontline workers who provide health services. Recent data from the USA, UK, and Germany suggests women in the pandemic era spend more time (previous and past) in childcare and home schooling than men do. ${ }^{1}$

There is a great deal of difficulty in the provision of regular health services for pregnant women as well those seeking contraceptive services. Access to essential sexual and reproductive health needs cannot be undermined in this overwhelming situation. However, the focus of health services is entirely trained toward provision of preventive and curative services in community and hospitals. A long lockdown cannot have the effect of pressing the pause button on female physiology.
Address for correspondence Poonam Malhotra Kapoor, MD, DNB, MNAMS, FISCU (Hon), FICTC (Hon), FTEE (Hon), Department of Cardiac Anaesthesia, Cardio Thoracic Centre, All India Institute of Medical Sciences, New Delhi, 110029, India (e-mail: drpoonamaiims@gmail.com).
DOI https://doi.org/ 10.1055/s-0040-1718505.

(C)2020 Women in Cardiology and Related Sciences

published online

October 9, 2020
License terms

() (1) $\Theta \circledast$ 
Therefore, routine pregnancy, childbirth, and immunization-related issues also demand attention from the medical fraternity. Women are also weighed down due to a stressful home environment as a result of lockdowns and work from home options. Therefore, it is very important on the part of physicians to be aware of these prevalent problems affecting women's health during the COVID-19 crisis.

\section{Why is there Equal Risk, Unequal Burden?}

It is important to know why gender differentials exist with regard to mortality on account of COVID-19 in India. Early evidence indicates that males have higher overall burden of contracting the infection, but females have a higher relative risk of COVID-19 mortality in India. Elderly males and females both display high-mortality risk and require special care when infected. Greater focus on data collection and sharing of age- and sex-specific COVID-19 cases and mortality data are necessary to develop robust estimates of COVID-19 case fatality in order to support policy decisions. ${ }^{2}$

If one assesses men versus women's health and how these factors intersect in the public health front, then it is clear that as more men are dying because of Coronavirus disease worldwide. What is it that is protecting the female gender? The overall COVID-19 case fatality ratio is approximately 2.4 times higher among men than women., ${ }^{2,3}$ This gender difference is not explained by any single biological or social factor but psychosocial and behavioral factors, as described by Griffith ${ }^{4}$ et al, which are related to the X chromosome and contain adaptive and innate immune responsive genes. These make women mount stronger innate and immune responses than men. It is dependent on sex-dependent production of steroid hormones, different copy numbers of immune response X-linked genes, and the presence of disease suscent genes, which makes the difference. Also, men carry higher plasma angiotensin-converting enzyme-2 (ACE-2) levels than women do, thus possibly reflecting higher tissue expression of the ACE-2 receptor for SARSCoV-2 infection. ${ }^{5}$ Therefore, men have greater chances of heart failure and susceptibility to SARS-CoV-2 in terms of entry into the body for other viral transmissions; however, this aspect needs further validation and research. ${ }^{5}$

\section{The Cytokine Storm too Hits Men Harder than Women}

The "cytokine storm" is very relevant to COVID-19 today! Plasma levels of interleukin (IL)-6 and other cytokines may not be representative of lung inflammation and severe endothelial dysfunction. ${ }^{6}$ We, as endotheliologists, should treat this cytokine storm of raised IL-6 and D-dimer levels like a tempest in a teapot, ${ }^{6}$ Being a female initiates nonspecific inflammation and molecular mimicry, which is mediated by T-lymphocytes. The resultant effect reflects the sum of the genetic, gender, and environmental factors involved. Old and young women alike produce more antibodies and a higher anti-inflammatory cytokine count-a sign of greater potential immunological overreaction than males. ${ }^{6}$ This is an old theory, but from the proceedings of the National Academy of Sciences, the higher level of testosterone levels indicates lower immunity to combat all bacterial, fungal, and viral infections as well as the cytokine $\operatorname{storm}^{7}(-$ Fig. 1).

\section{A Pandemic Magnifies All Existing Inequalities: Leadership Should Protect the Interest of the Female Gender}

This pandemic will silently kill "women's independence in the 2020 era." It should be safeguarded by the leaders and is entirely plausible. This negative effect of the pandemic should be overcome with the help of strong leadership! As countries with females as leaders have fared better in this COVID-19, it is wise to promote feminist leadership, which is transformative in nature, as it alters outcomes on the back of better social decisions, making gender equality a priority. It needs urgent protocolization and research globally to herald "women's equality." Leadership should protect the interests of the female gender. ${ }^{7}$

The COVID-19 infection is also challenging physicians in terms of atypical presentations and complicating already existing chronic diseases. Therefore, there is a need to prepare guidelines for management of this vulnerable and subtly attacked group.

The review of "Women in COVID-19 pandemic-beyond morbidity and mortality" in this distinctive issue of the IJCDW journal sums up the COVID-19 perspectives in relation to different medical fields such as rheumatology, obstetrics and gynecology, medicine, neurology, endocrinology, and community medicine. The cardiological aspect of COVID-19 in the resilient gender, dealing with acute coronary syndromes, cardiovascular comorbidities, and COVID-19 infection and its thromboembolic manifestations, is worth imbibing in our clinical perspective. The basic sciences and microbiology aspect of COVID-19 individual testing with respect to mass surveillance is lucidly described in this special COVID-19 issue of this successful journal. This article, which has been framed for the purpose of fighting for a common cause, is a must read.

Females are more adept than men in schooling their emotions; thus, they are more cooperative, more adaptive, and can more easily circumvent contentious arguments. Their greater self-awareness and emotional literacy help them overcome

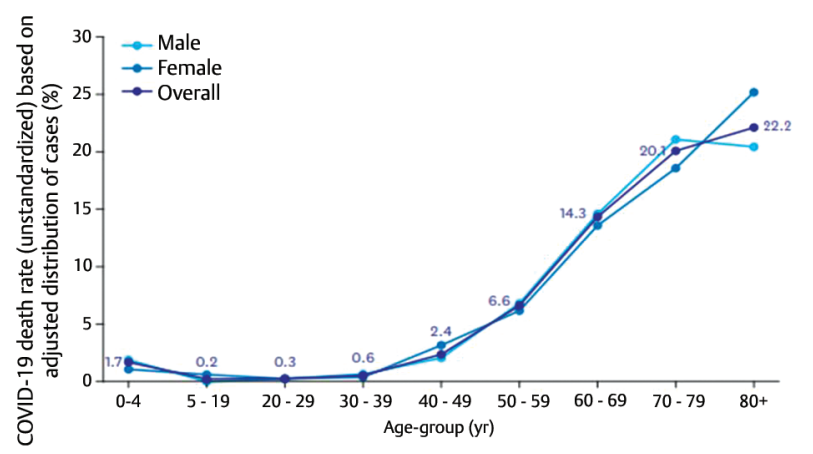

Fig. 1 Sex differentials in COVID-19 case fatality ratio (CFR), India. 
the Socratic examination of life and its adversity. "Adversity" said Shakespeare, "is like a jewel on the head of a toad." He did not include the COVID-19 pandemic, floods, Iran-Iraq war, etc. in the definition of adversity. The "ego resilience" in women is pointed out by Jack Block. "Adaptation to life" is viewed as a surrogate for emotional intelligence, much like SAT scores are for IQ! This is what aids in building immunity and adaptivity levels to deal with stress and COVID-like diseases with greater resolve.

"Perhaps the biggest challenge involved in the future will be to search for the environmental events that trigger self-reactivity," as quoted by Sinha et $\mathrm{al}^{5}$ and "protect the female gender." Involving competent females as leaders to protect their own gender is thus the need of the hour in this pandemic.

\section{Conflicts of Interest}

None declared.

\section{References}

1 Enarson E, Fothergill A, Peek L, Gender and disaster: foundations and new directions for research and practice. In: Havidan R, William D, Joseph ET, eds. Handbook of Disaster Research. Cham, Switzerland: Springer; 2018 205-223

2 Williams DR. The health of men: structured inequalities and opportunities. Am J Public Health 2003;93(5):724-731
3 White A, Richardson N. Gendered epidemiology: making men's health visible in epidemiological research. Public Health 2011;125(7):407-410

4 Griffith DM. Biopsychosocial approaches to men's health disparities research and policy. Behav Med 2016;42(3):211-215

5 Jack L, Jr, Griffith DM. The health of African American men: implications for research and practice. Am J Men Health 2013;7(4, Suppl):5S-7S

6 Sinha P, Matthay MA, Calfee CS. Is a cytokine storm relevant to COVID-19? JAMA Intern Med 2020;180(9):1152-1154

7 Girard O, Where are the women? The conspicuous absence of women in COVID-19 response teams and plans and why we need them. Care. Available at: https://www.care-international. org/files/files/CARE_COVID-19-womens-leadership-report June-2020.pdf. Accessed August 24, 2020.

8 Block J, Kremen AM. IQ and ego-resiliency: conceptual and empirical connections and separateness. J Pers Soc Psychol 1996;70(2):349-361 